ISAHP Article: A Style Guide for Paper Proposals To Be Submitted to the International Symposium of the Analytic Hierarchy Process 2016, London, U.K.

\title{
A survey of AHP and ANP applications in civil engineering and urban management
}

*Note: Do not include the author(s) names and information as this document will be blind reviewed and they will be entered during proposal submission.

\section{ABSTRACT}

Results of a survey of scientific works which deal with the application of AHP and ANP in civil engineering and urban management are presented in the paper. Dozens of books, journal articles, chapters in monographs and papers included in conference proceedings have been analysed with this regard. The survey delivers information about decision making problems in civil engineering and urban management solved by means of AHP and ANP. It also documents development of ways the techniques are applied to improve solutions of problems in both fields.

Keywords: AHP, ANP, application, survey, civil engineering, urban management.

\section{Introduction}

AHP and ANP belong to world-widely acknowledged decision making techniques which provide powerful and efficient means for modeling and solving diversified complex decision making problems in different areas. Civil engineering and urban management belong to application areas of the techniques which often appear in literature.

\section{Literature Review}

Both general surveys and profiled surveys deal with AHP and ANP applications. There is a lot of the applications available in the literature. Number of the applications increases instantly from a week to week. Therefore contemporary general surveys (e.g. Sipahi \& Timor 2010) are usually severily limited to selected application cases only. On the other hand it is easier for a profiled survey to list complete, or almost complete at least, set of up to date applications of the techniques that are related to distinct research areas. For example there is a profiled survey which deals with health care applications (Liberatore \& Nydick 2008). A universal nature of AHP and ANP causes that they are also applied alongside other tools for solving specific problems. That is why information about such applications also appears in surveys on such specialized applications (Chai et al. 2010, Dytczak 2010). However, there is a lack of an up-to-date comprehensive survey on the application of ANP and AHP in civil engineering and urban management. 


\section{Hypotheses/Objectives}

AHP and ANP prove useful tools which are capable of delivering reliable solutions to diverse decision-making problems in civil engineering and management. The techniques are applied in different ways to realize specific tasks.

\section{Research Design/Methodology}

A wide literature review was conducted to get information about available scientific works about AHP and ANP applications. Both acknowledged Internet data sources including web service of acknowledged scientific publishers (Elsevier, Springer and others), scientific serivces (e.g. Scopus), and general search engines had been utilized to get information about the applications of AHP and ANP.

\section{Data/Model Analysis}

Found scientific works were then analysed, classified and described.

\section{Limitations}

The authors made their best to give an exhaustive presentation of information about AHP/ANP applications. One should be nevertheless aware that new AHP/ANP applications in civil engineering still emerge. On the other hand information about some applications may be not available to the authors at all.

\section{Conclusions}

AHP and ANP are among decision support techniques that are often and willingly applied to solve decision making problems in civil engineering and urban management. They prove to be reliable tools to solve specific problems of diverse kinds. Their merits that result from their pair-wise comparison foundations makes them a superb means for complementing other tools (Ginda 2015). They are applied therefore in diverse ways to exploit synergy resulting from capability of other tools while solving specific decision making problems in civil engineering and urban management.

\section{Key References}

Sipahi, S., \& Timor, M. (2010). The analytic hierarchy process and analytic network process: an overview of applications. Management Decisions, 48(5), 775-808.

Liberatore, T.L., \& Nydick, K. (2008). The analytic hierarchy process in medical and health care decision making: A literature review, European Journal of Operational Research, 189(1), 194-207.

Chai, J., Liu, J.N.K., Ngai, N.W.T. (2013). Application of decision-making techniques in supplier selection: A systematic review of literature. Expert Systems with Applications, 40(10), 3872-3885.

Dytczak, M. (2010). Selected methods for multi-criteria decision analysis in civil engineering. Politechnika Opolska, Opole.

Ginda, G. (2015). Pair-wise comparison-based methods for decision making support in civil engineering and related fields. DWE, Wrocław. 